\title{
Factors Associated with Work Participation and Work Functioning in Depressed Workers: A Systematic Review
}

\author{
S. E. Lagerveld • U. Bültmann • R. L. Franche $\cdot$ F. J. H. van Dijk • \\ M. C. Vlasveld - C. M. van der Feltz-Cornelis • D. J. Bruinvels • \\ J. J. J. M. Huijs • R. W. B. Blonk · J. J. L. van der Klink • K. Nieuwenhuijsen
}

Published online: 21 January 2010

(C) The Author(s) 2010. This article is published with open access at Springerlink.com

\begin{abstract}
Background Depression is associated with negative work outcomes such as reduced work participation (WP) (e.g., sick leave duration, work status) and work functioning (WF) (e.g., loss of productivity, work limitations). For the development of evidence-based interventions to improve these work outcomes, factors predicting WP and WF have to be identified. Methods This paper presents a systematic literature review of studies identifying factors associated with WP and WF of currently depressed workers. Results A total of 30 studies were found that addressed factors associated with WP $(N=19)$ or WF $(N=11)$. For both outcomes, studies reported most often on the relationship with disorder-related factors, whereas personal factors and work-related factors were less
\end{abstract}

Electronic supplementary material The online version of this article (doi:10.1007/s10926-009-9224-x) contains supplementary material, which is available to authorized users.

S. E. Lagerveld ( $₫)$ · J. J. J. M. Huijs · R. W. B. Blonk TNO Quality of Life, Business Unit Work and Employment, P.O. Box 718, 130 AS Hoofddorp, The Netherlands e-mail: suzanne.lagerveld@ tno.nl

U. Bültmann · J. J. L. van der Klink

Department of Health Sciences, Section of Social Medicine,

Work \& Health, University Medical Center Groningen,

Groningen, The Netherlands

R. L. Franche

Occupational Health and Safety Agency for Healthcare

(OHSAH), Vancouver, Canada

F. J. H. van Dijk - D. J. Bruinvels - K. Nieuwenhuijsen

Coronel Institute of Occupational Health, Academic Medical

Center, Amsterdam, The Netherlands

M. C. Vlasveld · C. M. van der Feltz-Cornelis

Netherlands Institute of Mental Health and Addiction,

Utrecht, The Netherlands frequently addressed. For WP, the following relationships were supported: strong evidence was found for the association between a long duration of the depressive episode and work disability. Moderate evidence was found for the associations between more severe types of depressive disorder, presence of co-morbid mental or physical disorders, older age, a history of previous sick leave, and work disability. For WF, severe depressive symptoms were associated with work limitations, and clinical improvement was related to work productivity (moderate evidence). Due to the cross-sectional nature of about half of the studies, only few true prospective associations could be identified. Conclusion Our study identifies gaps in knowledge regarding factors predictive of WP and WF in depressed workers and can be used for the design of future research and evidence-based interventions. We recommend undertaking more longitudinal studies to identify modifiable

M. C. Vlasveld

Department of Public and Occupational Health, The EMGO Institute for Health and Care Research, VU University Medical Center, Amsterdam, The Netherlands

C. M. van der Feltz-Cornelis

Department of Clinical Psychology, University of Tilburg,

Tilburg, The Netherlands

C. M. van der Feltz-Cornelis

GGZ Breburg, Breda, The Netherlands

R. W. B. Blonk

Department of Social and Organizational Psychology,

Utrecht University, Utrecht, The Netherlands 
factors predictive of WP and WF, especially work-related and personal factors.

Keywords Depressive disorder - Occupational health · Work disability · Workplace - Sick leave · Unemployment

\section{Introduction}

\section{Depression in the Workforce}

Depression is known to affect many aspects of life, including work [1]. The 12-month prevalence rates of depression in the working population vary between 3.4 and $6.0 \%$ for mood disorder in European countries [2, 3] and is $6.4 \%$ for major depressive disorder in the United States [4]. Many workers experience negative effects of the depressive disorder on functioning at work $[1,5]$. Next to individual suffering, depression-related work problems have high cost implications for employers and society [5, 6]. Adverse consequences of depression on work can be indexed by different work outcome measures, such as presenteeism, productivity loss, decrease in work quality, mistakes and errors, work accidents, sickness absence, disability pensions and unfavorable career perspectives. The different work outcomes can be conceptualized as either addressing "Work Participation" or "Work Functioning".

\section{Impact of Depression on Work Participation}

Work participation (WP) has been conceptualized in this paper as the capability and/or opportunity to participate in the workforce, fulfilling one's work role. This includes 'time-based measures' (e.g., time to return to work) and status-based measures (e.g., work status). Participation problems can include serious problems to enter the labor market, short-term work disability such as episodes of absenteeism, long-term or permanent work disability and employment termination such as unemployment or early retirement. Several studies show that WP is substantially affected by depression, but the magnitude and nature of the effects described vary across the work outcome measures used, the study populations and study settings.

The effect of depression on WP has been the topic of several large epidemiological studies. Some of these studies compare the WP of a non-depressed group with a clinically depressed group, whereas, other studies relate the level of depressive symptoms of persons in the general population to their level of work participation. Studies in non-clinical populations have, for example, examined the relationship between depressive symptoms and (long-term) sickness absence [7, 8], disability pension award [9], and unemployment [10]. Other studies that compare clinically depressed groups with other non-depressed groups show that depressed workers have more short-term work disability compared to non-depressed workers and, interestingly, compared to workers with a physical condition [11, 12]. In addition, depression in workers has been associated with a longer duration of sickness absence compared to non-depressed workers [1, 13]. Lerner and Henke [1] reviewed several clinical, population-based and worksite studies and found that, compared to non-depressed individuals, those with depression have more work absences and more instances of new unemployment. The impact of depression on unemployment has been the topic of various other studies. Cross-sectional population-based studies revealed higher rates of unemployment in depressed groups [14-16]. The assumption that depression is a risk factor for subsequent job loss is substantiated by longitudinal studies in employed primary care patients [11], young workers [10], and aging workers [17]. Finally, some studies indicate that depressed workers have more early retirement [18] compared to workers without depression.

\section{Impact of Depression on Work Functioning}

The work functioning of workers suffering from depression is (adversely) affected in various ways [1]. Work functioning refers to the productivity or performance of employees that participate, at least partly, in work, and is the result of a relationship between an individual's health resources and the expectations and structural conditions that operate within social settings such as the workplace [19]. So where work participation differentiates between people 'off work' or 'at work', work functioning is an 'at work measure', distinguishing between individuals that function differently at work. Work functioning has been categorized in this paper as proposed by Amick and Gimeno [20]. They describe two categories of work functioning that can be used to describe the impact of a health condition. The first category deals with the economic consequences of health conditions such as, self-reported loss of productivity at the job [5, 21]. Depression has been associated with such decrements in work productivity [2123]. The second category quantifies the impact of a health condition on work role functioning by the limitations that workers experience in fulfilling their work tasks. Studies on depressed workers have demonstrated difficulty in meeting mental-interpersonal demands, time management demands, output demands and, in some cases, physical demands [11, $22,24,25]$. In addition to the reported decrease in work productivity and increase in work limitations, Dewa and Lin [26] demonstrated that workers with depression could only achieve acceptable work functioning with extra effort. Depressed workers reported, on average, 11.6 of these 'extra effort days' in the previous 30 days. 
Need for Development and Evaluation of Interventions

Considering the severe consequences of depression, it is important that effective interventions with respect to work functioning and work participation be available. A recent Cochrane review on depressive disorders showed, however, that the evidence for the effectiveness of existing worker-directed 'clinical' interventions on work outcomes was limited [27]. Nieuwenhuijsen et al. conclude that it remains unclear whether worker- or work-directed interventions can reduce sickness absence in depressed workers. In this Cochrane review, no studies reporting on workplace interventions were found, and only one study addressed work issues as part of the clinical treatment [28]. Based on these results, it can be concluded that a need exists to develop and evaluate interventions that enhance work functioning and work participation in depressed workers. This notion is supported by Lerner and Henke [1] who stress the need to develop intervention programs, especially interventions that address workplace issues.

To develop new interventions, it is important to know which factors influence work participation and work functioning. Although the existing literature includes many studies on the relationship between depression and work outcomes, it remains largely unclear which factors might enhance or hinder favorable work outcomes for workers who are currently depressed.

A multidisciplinary expert group including researchers and care providers, identified possible predictive factors of work outcomes departing from the WHO ICF model [29]. This model was selected because it provides broad view on predictors of functioning and participation in work, taking the multidimensional nature of these concepts into account. This broad 'biopsychosocial' perspective might offer new opportunities for interventions as compared to traditional medical models. In accordance to the study of Sanderson [30] who applied the ICF to a population of workers with mental health problems, work functioning and work participation can be situated in the ICF domains 'Activities' (e.g., limitations in work activities or performance) and 'Participation' (e.g., absenteeism). The expert group brainstormed on possible predictive factors for both work outcomes in depressed workers focusing on personal, work-related and disorder-related factors corresponding to the contextual ICF categories person and environment (here work environment), and to the health condition [31]. Modifiable factors mentioned at the personal level concerned e.g., coping/ appraisal, self-efficacy, professional competence and perfectionism. With respect to the work environment, factors such as work demands, workplace culture, social support, job insecurity and decision latitude were mentioned. With respect to disorder-related factors, number of episodes, type of depressive disorder and co-morbidity were highlighted.
To evaluate the impact of these possible predictive factors identified as relevant by the expert group, we have conducted a systematic review of the scientific literature on factors related to WF and WP problems among currently depressed workers. The results will help to provide an evidence-based ground for the development of intervention programs to enhance work functioning and work participation, and will point out gaps in scientific evidence that need to be addressed in future research.

\section{Methods}

\section{Literature Search}

For WF and WP, two complementary searches were conducted in three literature databases (PsycINFO, PubMed and Scopus). Original studies (in English) were identified that were published from 1995 to 2008. No restrictions with respect to the study design were applied. The search strategies consisted of a depression component (e.g., depressive disorder) and either a WF component (e.g., work productivity, work limitations) or a WP component (e.g., return-towork, disability benefits, absenteeism, turnover, job loss). In "Appendix 1" the search terms are presented. The following eligibility criteria were defined: (1) Studies reported on factors related to WF or WP outcome in depressed workers, (2) Study samples included at least 50\% employed participants or provided subgroup (or interaction) analysis for the employed participants, (3) Depression was defined as dysthymic disorder, minor depressive disorder or major depressive disorder, (4) Depression had to be diagnosed by an expert (e.g., following DSM-IV [32] or ICD-10 [33] criteria), or had to be based on a well-defined cut-off score for depressive symptoms of a validated self-report instrument (e.g., BDI [34], HDRS [35], or CES-D [36]. If samples consisted partly of non-depressed workers, only studies that conducted subgroup (or interaction) analysis with depressed workers were included. After the screening of titles and abstracts, inclusion of potential relevant studies was evaluated by at least two authors. We excluded studies of bipolar or schizophrenic disorders, those with a sample selection based on physical/somatic complaints, and those including a depressed sample in which all participants had a severe physical/somatic illness such as cancer or multiple sclerosis. Reviews were excluded, but reference lists were inspected for additional studies. If the title and the abstract provided no information about depressed or employed participants, a WF or WP outcome measure or a related factor, we excluded the studies. If the title and the abstract provided insufficient information about the proportion of depressed or employed participants, we retrieved the full publication. 
Assessment of Methodological Quality of Included Studies

The distinction between cross-sectional and longitudinal studies is the one aspect of methodological quality that was incorporated in our evidence synthesis. However, to increase transparency and accurate documentation, a more elaborate assessment of methodological quality was conducted. No single instrument to assess quality in observational studies can be identified as the gold standard [37, 38]. However, the authors of a recent review of available instruments [38] suggested that such an instrument should cover three fundamental domains: selection of participants, measurement of variables, and control of confounding. The 10-item instrument that was designed for this study covers those three domains along with accurate reporting of main features of study population, data analysis, data presentation, and power (see "Appendix 2" for the full items). The individual items of the checklist were rated by two independent reviewers as either positive (score 1) or negative/unable to determine (score 0). Any difference between the reviewers was discussed until consensus was reached. In accordance with the recommendations by Sanderson et al. [38] we made no summary judgment of low versus high quality.

\section{Evidence Synthesis and Grouping of Work-related} Outcome Measures

For the purpose of synthesizing the results we clustered similar work outcomes. Two different WP outcomes emerged: work disability and termination of employment. Work disability was considered as depression-related inability to work, for a short period (temporarily) or longer periods (even permanently). Outcome measures for work disability included sickness absence or absenteeism, return to work, and disability benefits. Terminating employment was defined as voluntary or involuntary (partly) leaving the workforce, when no health reasons were mentioned. Outcome measures for terminating employment included (early) retirement, job loss or unemployment, quitting and decreasing contract working hours.

WF outcomes included work limitations, such as difficulties in meeting certain demands of the job and work productivity (e.g., lost productive time or inefficient days). When both univariate and multivariate analyses were presented, the multivariate results were incorporated in the result tables. When multiple similar work outcome measures were used in one study, the outcome with highest information value was used, i.e., a continuous work disability measure was preferred to a dichotomous work disability measure.

Based on Ariens et al. [39], the level of evidence for the association with WP or WF was rated for each factor according to the following grading:
1. Strong evidence: consistent findings of at least two longitudinal studies

2. Moderate evidence: consistent findings of at least two studies of which only one is a longitudinal study, or consistent findings of at least two longitudinal studies, but one cross-sectional study opposing these results.

3. Limited evidence, three possibilities: findings of only one longitudinal study, or consistent findings of at least two cross-sectional studies, or two longitudinal studies with consistent findings, but two cross-sectional studies opposing these results.

4. Inconclusive evidence: all other findings e.g., opposing findings of at least two studies, findings of only one cross-sectional study or no studies with significant findings available.

Consistent findings were defined as studies demonstrating significant relationships in the same direction, either positive or negative. Results were considered 'opposing' when both positive and negative relationships were present at the same time. Studies without significant findings were considered neither consistent nor opposing.

\section{Results}

Description of Inclusion and Exclusion

The electronic literature search resulted in 317 hits for WP and 629 hits for WF that were screened for eligibility. Based on title and abstract, 71 articles were full-text reviewed (53 WP and $18 \mathrm{WF}$ ). Of these 71 articles, 41 were excluded for various reasons. Nine articles were reviews. Screening the reference lists of these reviews resulted in two additional WP publications [40, 41]. The main reason for excluding the other 32 publications was that no factors related to WP or WF were presented for a depressed (sub-)group (22 studies). These studies compared, for example, a depressed and a non-depressed group on work outcomes, or the effect of an intervention on work outcomes in a depressed population. Other reasons for exclusion were: no WP outcome was included (3 studies), participants were not employed at baseline or their work status was unclear (4 studies), or the full text was not available (3 studies). In total, 30 studies were selected (19 WP, 11 WF). Because five of these studies addressed both WP and WF, 25 unique publications could be identified, based on data from 10 industrialized countries such as USA, Australia, Canada, and several European countries. In Table 1 an overview of the selected studies can be found. More detailed information about the work outcome, related factors, study population, depression measure, study design, and the main findings of each 
Table 1 Overview of studies

\begin{tabular}{|c|c|c|c|c|c|c|c|}
\hline & Study ID & Year & Country & $n$ & Population & Design & Outcome \\
\hline 1 & Birnbaum et al. [69] & 2003 & USA & 5,295 & Non specified group of workers & $\mathrm{C}$ & WP \\
\hline 2 & $\begin{array}{l}\text { Buist-Bouwman } \\
\text { et al. [70] }\end{array}$ & 2005 & The Netherlands & 573 & Non specified group of workers & $\mathrm{C}$ & WP \\
\hline 3 & Dewa et al. [71] & 2002 & Canada & 1,521 & Workers in finance and insurance industry & $\mathrm{C}$ & WP \\
\hline 4 & Dewa et al. [72] & 2003 & Canada & 997 & Workers in finance and insurance industry & $\mathrm{L}$ & WP \\
\hline 5 & Druss et al. [12] & 2000 & USA & 412 & Workers in manufacturing industry & $\mathrm{C}$ & WP \\
\hline 6 & Kruijshaar et al. [42] & 2003 & The Netherlands & 439 & Non specified group of workers & $\mathrm{C}$ & WP \\
\hline 7 & $\begin{array}{l}\text { Laitinen-Krispijn } \\
\text { and Bijl [43] }\end{array}$ & 2000 & The Netherlands & 233 & Non specified group of workers & $\mathrm{L}$ & WP \\
\hline 8 & Lepine et al. [41] & 1997 & $\begin{array}{l}\text { Belgium, France, Germany, } \\
\text { The Netherlands, Spain, } \\
\text { UK }\end{array}$ & 13,359 & Non specified group of workers & $\mathrm{C}$ & WP \\
\hline 9 & Nieuwenhuijsen et al. [63] & 2004 & The Netherlands & 49 & Non specified group of workers & $\mathrm{C}$ & WP \\
\hline 10 & Rytsälä et al. [73] & 2005 & Finland & 269 & Non specified group of workers & $\mathrm{C}$ & WP \\
\hline 11 & Rytsälä et al. [74] & 2007 & Finland & 186 & Non specified group of workers & $\mathrm{L}$ & WP \\
\hline 12 & Simon et al. [40] & 2000 & USA & 229 & Non specified group of workers & $\mathrm{L}$ & WP \\
\hline 13 & Sorvaniemi et al. [75] & 2003 & Finland & 185 & Non specified group of workers & $\mathrm{C}$ & WP \\
\hline 14 & Souêtre et al. [76] & 1997 & France & 345 & Non specified group of workers & $\mathrm{C}$ & WP \\
\hline 15 & Claassen et al. [77] & 2007 & USA & 2,341 & Non specified group of workers & $\mathrm{C}$ & $\mathrm{WP}$ and $\mathrm{WF}$ \\
\hline 16 & Druss et al. [68] & 2001 & USA & 1,200 & Non specified group of workers & $\mathrm{L}$ & $\mathrm{WP}$ and $\mathrm{WF}$ \\
\hline 17 & Lerner et al. [11] & 2004 & USA & 229 & Non specified group of workers & $\mathrm{L}$ & $\mathrm{WP}$ and $\mathrm{WF}$ \\
\hline 18 & Sanderson et al. [22] & 2007 & Australia & 49 & Workers in call centres & $\mathrm{L}$ & $\mathrm{WP}$ and $\mathrm{WF}$ \\
\hline 19 & Stewart et al. [21] & 2003 & USA & 219 & Non specified group of workers & $\mathrm{C}$ & $\mathrm{WF}$ and $\mathrm{WF}$ \\
\hline 20 & Adler et al. [24] & 2006 & USA & 286 & Non specified group of workers & $\mathrm{L}$ & WF \\
\hline 21 & Endicott and Nee [78] & 1997 & USA & 77 & Non specified group of workers & $\mathrm{C}$ & WF \\
\hline 22 & Hawthorne et al. [79] & 2003 & Australia & 390 & Non specified group of workers & $\mathrm{C}$ & WF \\
\hline 23 & Kornstein et al. [80] & 2000 & USA & 390 & Non specified group of workers & $\mathrm{C}$ & WF \\
\hline 24 & Lerner et al. [81] & 2004 & USA & 246 & Non specified group of workers & $\mathrm{C}$ & WF \\
\hline 25 & Michon et al. [82] & 2008 & The Netherlands & 184 & Non specified group of workers & $\mathrm{L}$ & WF \\
\hline
\end{tabular}

Design: $L$ longitudinal, $C$ cross-sectional

Outcome: $W F$ work functioning, WP work participation

of these publications is summarized in a data extraction form (Electronic supplementary material).

\section{Methodological Quality of Included Studies}

About half of the studies had a cross-sectional design, while the other half used longitudinal data. All but three studies [21, 22, 42] were deemed to have sufficient statistical power. The mean overall quality score of the studies was fairly high, i.e. 7.9 for WF and 8.2 for WP, with a range from 4 to 10 . The complete results of the quality assessment of the included studies can be found in "Appendix 2".

Results from the Literature Search

The main results of the 30 included studies are reported in the Tables 2, 3, and 4, presenting relationships of personal, work-related, and disorder-related factors with both WP and WF outcomes, respectively. The WP and WF outcomes that are reported in these tables are all stated in a negative direction, e.g., more work limitations, lower work productivity, higher risk for work disability, or longer duration of work disability.

\section{Personal Factors}

As shown in Table 2, a total of 12 unique studies (10 WP, $2 \mathrm{WF}$ ) reported on personal factors. The studies included both WP outcomes (short-term and/or long-term work disability and employment termination). In addition, one WF outcome was addressed (work limitations). Risk factors for increased work disability were older age and previous spells of sick leave (moderate evidence), lower education, low self-esteem, feelings of hopelessness about the future, and low social functioning (all limited 
Table 2 Personal factors related to work participation (WP) and work functioning (WF) of currently depressed workers

\begin{tabular}{|c|c|c|c|c|c|c|}
\hline Related factor & Outcome & $D$ & $N$ & $R$ & Ref nr. & Conclusion \\
\hline \multirow[t]{10}{*}{ Gender (male) } & WP: work disability & A & 233 & + & Laitinen-Krispijn and Bijl [43] & \multirow[t]{8}{*}{ Inconclusive } \\
\hline & & A & 186 & + & Rytsala et al. [74] & \\
\hline & & A & 5,295 & - & Birnbaum et al. [69] & \\
\hline & & A & 5,295 & $=$ & Birnbaum et al. [69] & \\
\hline & & B & 1,521 & + & Dewa et al. [71] & \\
\hline & & B & 269 & - & Rytsala et al. [73] & \\
\hline & & B & 345 & $=$ & Souêtre et al. [76] & \\
\hline & & B & 997 & $=$ & Dewa et al. [72] & \\
\hline & WP: terminating employment & B & 1,521 & + & Dewa et al. [71] & Inconclusive \\
\hline & WF: work limitations & B & 390 & + & Kornstein et al. [80] & Inconclusive \\
\hline \multirow[t]{8}{*}{ Age (older) } & WP: work disability & A & 186 & + & Rytsala et al. [74] & \multirow{7}{*}{$\begin{array}{l}\text { Moderate evidence for positive } \\
\text { relation }\end{array}$} \\
\hline & & A & 185 & + & Sorvaniemi et al. [75] & \\
\hline & & B & 269 & + & Rytsala et al. [73] & \\
\hline & & B & 1,521 & + & Dewa et al. [71] & \\
\hline & & B & 412 & - & Druss et al. [12] & \\
\hline & & B & 997 & $=$ & Dewa et al. [72] & \\
\hline & & B & 345 & $=$ & Souêtre et al. [76] & \\
\hline & WP: terminating employment & B & 1,521 & \pm & Dewa et al. [71] & Inconclusive \\
\hline \multirow[t]{2}{*}{ Education (higher) } & WP: work disability & A & 186 & - & Rytsala et al. [74] & \multirow{2}{*}{$\begin{array}{l}\text { Limited evidence for negative } \\
\text { relation }\end{array}$} \\
\hline & & A & 185 & $=$ & Sorvaniemi et al. [75] & \\
\hline \multirow[t]{2}{*}{ Marital status } & WP: work disability & A & 186 & $=$ & Rytsala et al. [74] & \multirow[t]{2}{*}{ Inconclusive } \\
\hline & & $\mathrm{B}$ & 345 & $=$ & Souêtre et al. [76] & \\
\hline \multirow[t]{2}{*}{ History of sick leave } & WP: work disability & A & 186 & + & Rytsala [749] & \multirow{2}{*}{$\begin{array}{l}\text { Moderate evidence for positive } \\
\text { relation }\end{array}$} \\
\hline & & $\mathrm{B}$ & 345 & + & Souetre [761] & \\
\hline \multirow[t]{2}{*}{ Low Self-esteem } & WP: work disability & A & 185 & + & Sorvaniemi et al. [75] & $\begin{array}{l}\text { Limited evidence for positive } \\
\text { relation }\end{array}$ \\
\hline & WF: work limitations & A & 184 & + & Michon et al. [82] & $\begin{array}{l}\text { Limited evidence for positive } \\
\text { relation }\end{array}$ \\
\hline Hopeless about future & WP: work disability & A & 186 & + & Rytsala et al. [74] & $\begin{array}{l}\text { Limited evidence for positive } \\
\text { relation }\end{array}$ \\
\hline Low social functioning & WP: work disability & A & 186 & + & Rytsala et al. [74] & $\begin{array}{l}\text { Limited evidence for positive } \\
\text { relation }\end{array}$ \\
\hline Higher neuroticism & WF: work limitations & A & 184 & + & Michon et al. [82] & $\begin{array}{l}\text { Limited evidence for positive } \\
\text { relation }\end{array}$ \\
\hline More external locus of control & WF: work limitations & A & 184 & + & Michon et al. [82] & $\begin{array}{l}\text { Limited evidence for positive } \\
\text { relation }\end{array}$ \\
\hline \multirow[t]{2}{*}{ Alcoholism/substance abuse } & WP: work disability & A & 186 & $=$ & Rytsala et al. [74] & \multirow[t]{2}{*}{ Inconclusive } \\
\hline & & B & 269 & $=$ & Rytsala et al. [73] & \\
\hline Social adjustment & WP: work disability & A & 186 & $=$ & Rytsala et al. [74] & Inconclusive \\
\hline Social support & WP: work disability & A & 186 & $=$ & Rytsala et al. [74] & Inconclusive \\
\hline Living area & WP: work disability & B & 345 & $=$ & Souêtre et al. [76] & Inconclusive \\
\hline Income level & WP: work disability & B & 345 & $=$ & Souêtre et al. [76] & Inconclusive \\
\hline
\end{tabular}

$D$ design of study (A longitudinal, $B$ cross-sectional), $N$ total of participants from the sample fitting the inclusion criteria (depressed and employed) at baseline, $R$ relationship between factor and outcome. - , A negative relationship between factor and outcome; =, No significant $(p \leq .05)$ positive or negative relations found between factor and outcome; + , A positive relationship between factor and outcome; \pm , Opposing relations with the outcome are present for different levels of the factor (non linear relation)

evidence). Although gender was frequently studied in relation to work disability, no clear association could be found because of conflicting results. All other relations between personal factors and WP outcomes also remained inconclusive, mostly because of single cross-sectional studies or non-significant findings.

Two studies were identified that reported on WF related to gender and personality traits. Higher neuroticism, more 
Table 3 Work factors related to work participation (WP) and work functioning (WF) of currently depressed workers

\begin{tabular}{|c|c|c|c|c|c|c|}
\hline Related factor & Outcome & $D$ & $N$ & $R$ & Ref nr. & Conclusion \\
\hline Full-time employment & WP: work disability & $\mathrm{B}$ & 345 & + & Souêtre et al. [76] & Inconclusive \\
\hline Type of financial reward (wages) & WP: work disability & $\mathrm{B}$ & 345 & + & Souêtre et al. [76] & Inconclusive \\
\hline \multirow[t]{2}{*}{ Type of company } & \multirow[t]{2}{*}{ WP: work disability } & $\mathrm{B}$ & 345 & $=$ & Souêtre et al. [76] & \multirow[t]{2}{*}{ Inconclusive } \\
\hline & & $\mathrm{B}$ & 997 & \pm & Dewa et al. [72] & \\
\hline \multirow[t]{4}{*}{ Holding a managerial position } & \multirow[t]{3}{*}{ WP: work disability } & A & 185 & $=$ & Sorvaniemi et al. [75] & \multirow[t]{3}{*}{ Inconclusive } \\
\hline & & $\mathrm{B}$ & 345 & + & Souêtre et al. [76] & \\
\hline & & $\mathrm{B}$ & 1,521 & $=$ & Dewa et al. [71] & \\
\hline & WP: terminate employment & $\mathrm{B}$ & 1,521 & $=$ & Dewa et al. [71] & Inconclusive \\
\hline $\begin{array}{l}\text { Type of occupation (sales, service } \\
\text { or support vs. other) }\end{array}$ & WF: work limitations & $\mathrm{B}$ & 246 & + & Lerner et al. [81] & Inconclusive \\
\hline Low level of functioning at work & WP: work disability & A & 186 & + & Rytsala et al. [74] & $\begin{array}{l}\text { Limited evidence for positive } \\
\text { relation }\end{array}$ \\
\hline Frequent contact by supervisor & WP: work disability & A & 49 & + & Nieuwenhuijsen et al. [63] & $\begin{array}{l}\text { Limited evidence for positive } \\
\text { relation }\end{array}$ \\
\hline $\begin{array}{l}\text { Supervisor contacts other } \\
\text { professionals besides OP }\end{array}$ & WP: work disability & A & 49 & - & Nieuwenhuijsen et al. [63] & $\begin{array}{l}\text { Limited evidence for negative } \\
\text { relation }\end{array}$ \\
\hline Supervisor promotes gradual RTW & WP: work disability & A & 49 & $=$ & Nieuwenhuijsen et al. [63] & Inconclusive \\
\hline
\end{tabular}

$D$ design of study ( $A$ longitudinal, $B$ cross-sectional), $N$ total of participants from the sample fitting the inclusion criteria (depressed and employed) at baseline, $R$ relationship between factor and outcome. - , A negative relationship between factor and outcome; $=$, No significant $(p \leq .05)$ positive or negative relations found between factor and outcome; + , A positive relationship between factor and outcome; \pm , Opposing relations with the outcome are present for different levels of the factor (non linear relation)

external locus of control, and lower self-esteem were related to more limitations in work functioning (limited evidence). With respect to gender, no conclusive evidence was found because the single study, illustrating greater work limitations in men, used a cross-sectional design.

\section{Work-Related Factors}

Table 3 shows that seven (6 WP, 1 WF) out of the 30 studies reported on workplace factors. The selected studies included (short-term and/or long-term) work disability and employment termination (in this case a composite measure of termination, retirement or quitting) as WP outcomes, and work limitations as a WF outcome. The work-related factors in these studies included: employment characteristics (hours employed i.e., full-time versus part-time, type of financial reward (i.e., wages versus fees), managerial or non-managerial position, type of company, type of occupation), supervisory behavior, and previous functioning at work.

Work-related factors studied in relation to WP resulted often in inconclusive evidence because results were provided by single cross-sectional studies or studies without significant results. This is the case for hours employed, type of financial rewards, type of company (i.e., private, administration or self-employed), type of occupation and position. For a few work-related factors linked to the worker or the supervisor, evidence for a relationship with WP could be established. Limited evidence was found that increased work disability is associated with a 'previous low level of functioning at work'. Frequent contact by the supervisor during sick leave increased time until full RTW in the subgroup of depressed workers (limited evidence). However, contact between supervisor and other professionals besides the occupational physician, leads to shorter time to RTW (limited evidence).

The only work-related factor showing an association with WF was type of occupation (i.e., sales, service or support occupations compared to production, construction, repairs, transport occupations), but evidence remained inconclusive as only a single cross-sectional study reported on this relationship.

\section{Disorder-Related Factors}

Table 4 shows that 24 studies (17 WP, $7 \mathrm{WF}$ ) reported on disorder-related factors. The studies included both WP outcome clusters (short- or long-term work disability and employment termination) and both WF outcomes (work productivity and work limitations). Several disorder-related factors, that might somewhat overlap, were addressed: severity of depressive symptoms, type of the disorder (major depressive disorder (MDD), mild/minor depression, dysthymia), duration of the depression (single episodes, recurrences, chronic depression), clinical history (previous episodes, suicide attempts), clinical improvement of depression (no recovery), and co-morbidity (mental and/or physical disorders). 


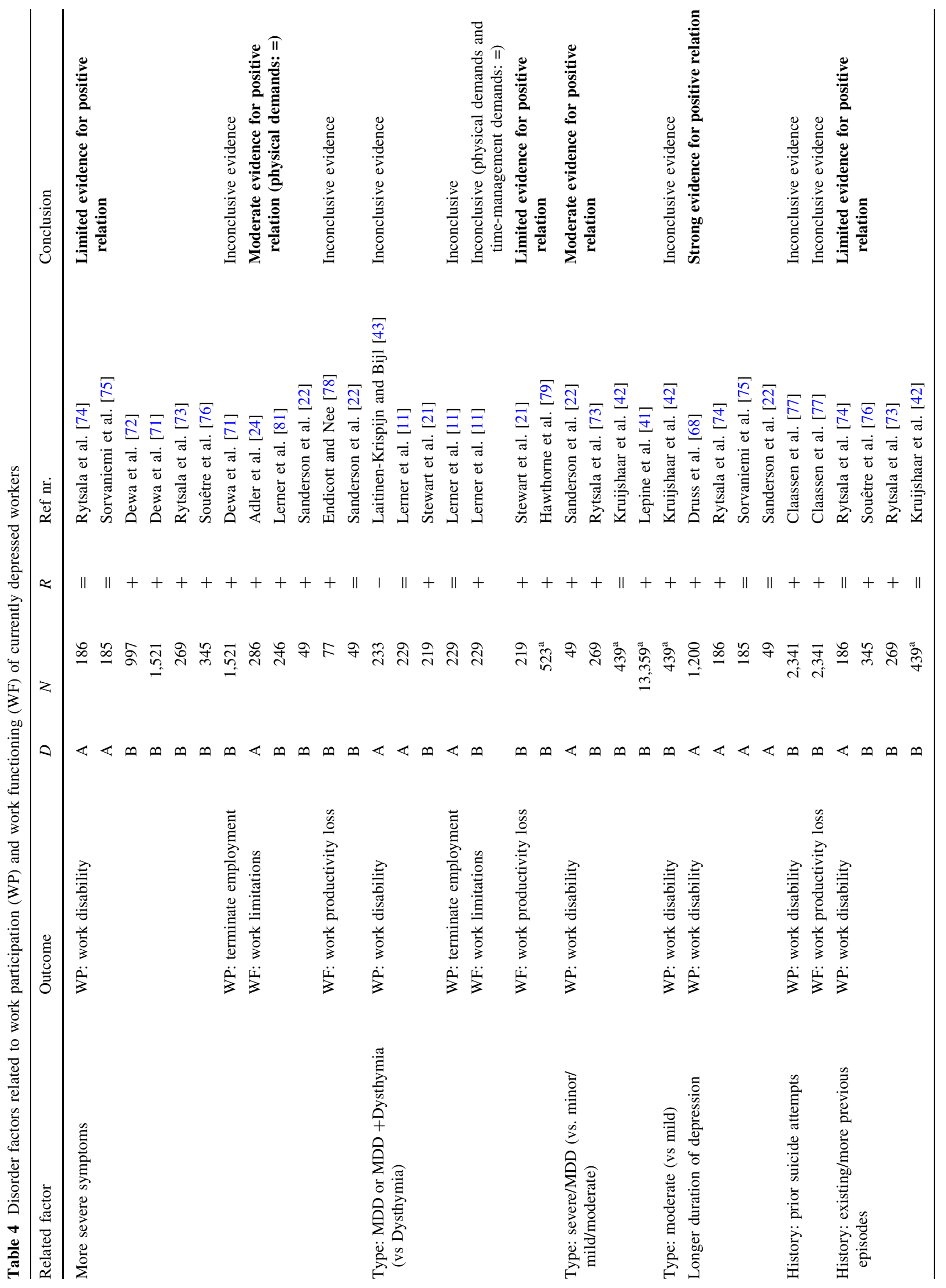




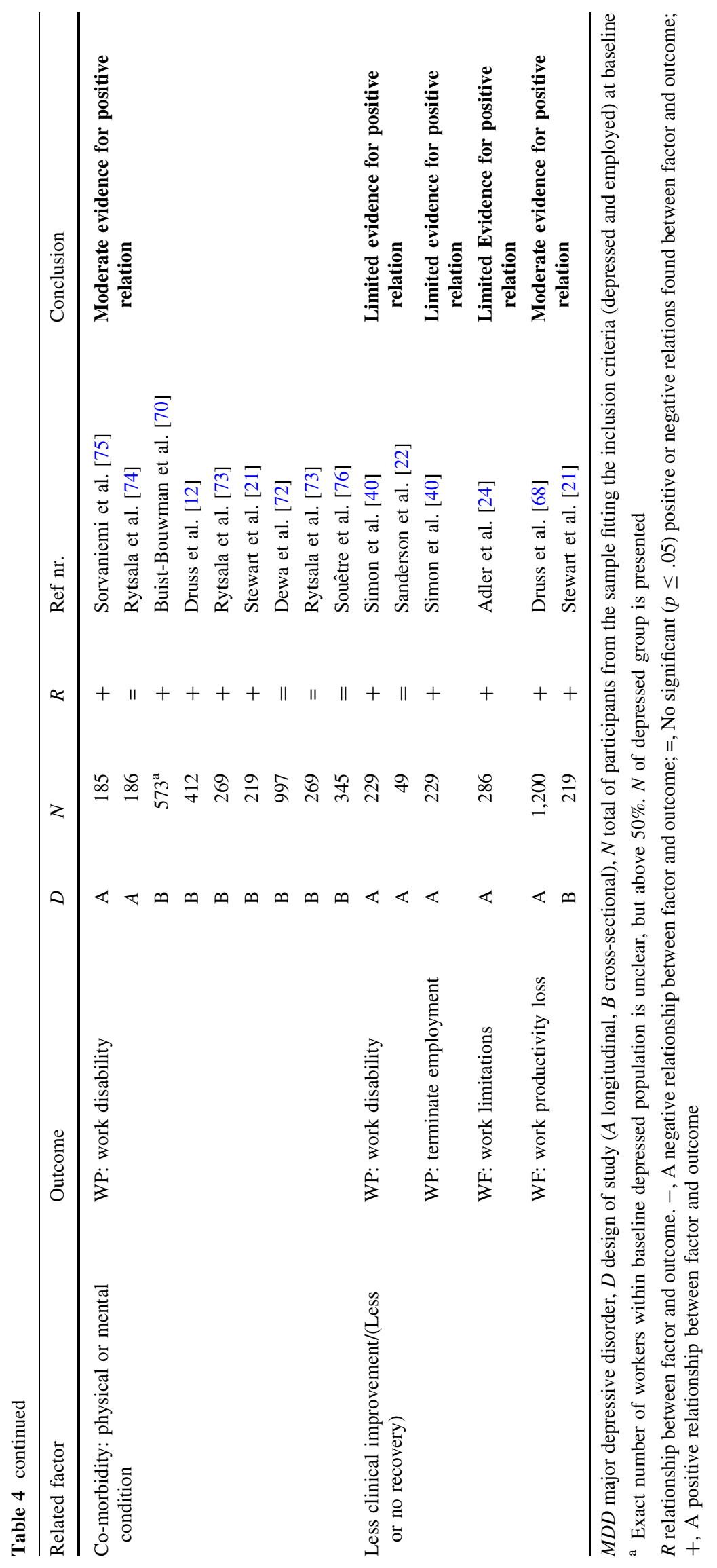


All factors were studied in relation to work disability. Increased work disability was associated with: longer duration of the current episode (strong evidence), MDD (moderate evidence), co-morbid mental or physical disorders (moderate evidence), more severe symptoms (limited evidence), more previous episodes (limited evidence), and less clinical improvement (limited evidence). In line with the results on work disability, less clinical improvement is related to employment termination (limited evidence).

Over one-third of the relationships with disorder-related factors were not significantly related to WP. However, those studies which did find a relationship did so in the expected direction: more symptoms, more severe type of disorder such as MDD, less clinical improvement, and the presence of comorbid disorders were all associated with less WP. One exception is the cross-sectional study of Laitinen-Krispijn [43] which found that in a subgroup of depressed men, those with dysthymia, had a higher risk of work absence compared to those with MDD. In addition, it is interesting to note that higher symptom severity was consistently related to unfavorable WP outcomes in cross-sectional studies, but not in the two longitudinal studies that were found.

With respect to WF, three studies, of which one had a longitudinal design, showed that more severe symptoms were associated with more work limitations in terms of mental-interpersonal demands, output demands, and time management demands, but not with physical demands (moderate evidence). In addition, less clinical improvement was related to increased work limitation (limited evidence). Impaired work productivity was associated with less clinical recovery (moderate evidence), and with MDD (or MDD with dysthymia) when compared to employees with dysthymia only (limited evidence). In general, WF is less studied compared to WP for the disorder-related factors, but as with WP, all relationships were in the expected direction and non-significant results were not often reported.

\section{Discussion}

This systematic literature review on personal, work-related and disorder-related factors associated with work participation (WP) or work functioning (WF) among depressed workers identified 30 studies. The results show that disorder-related factors were studied most often, followed by personal factors and work-related factors. Our study identifies several gaps in knowledge regarding factors related to WP and WF problems in depressed workers and provides valuable information needed to design future research. In particular, modifiable work-related and personal factors should be addressed in further research. The presented overview of factors related to WF and WP in depressed workers may also be useful for various stakeholders and professionals wanting to develop occupational health interventions for this population.

\section{Summary of Review Findings}

With respect to WP, the following relationships were supported by the literature. Strong evidence was found for the association between a long duration of depression and more (short-term and/or long-term) work disability. Moderate evidence was obtained for a relationship between more severe types of depressive disorders, presence of co-morbid mental or physical disorders, older age, history of previous sick leave, and work disability. Limited evidence was found to support a relationship between increased work disability, and low education, low self-esteem, feelings of hopelessness, low social functioning, impaired previous work functioning, supervisory behavior, severe depressive symptoms, previous depressive episodes, and little clinical improvement. Other participation outcome measures, such as unfavorable career perspectives, were studied less often. We found limited evidence for an association between less clinical recovery and termination of employment.

Regarding WF, moderate evidence was found for more severe symptoms to be associated with more work limitations, and for less clinical improvement of depression to be related to decreased work productivity.

Although limited to strong evidence could be established for some associations, many other relationships yielded inconclusive evidence, often due to a lack of longitudinal studies, hindering the identification of prospective relationships. In addition to the inconclusive evidence, a complete absence of studies (either cross-sectional or longitudinal) was observed for many possible combinations between potential predictors and work outcomes. For example, the type of financial reward was studied in relation to work disability, but not to other WP measures or any of the WF outcomes. This gap in the literature was predominantly present with respect to work-related factors, WF outcomes and certain WP outcomes, such as negative career perspectives.

\section{Comparison and Contrast with Other Mental and Somatic Health Disorders}

No other systematic review describing predictors of work functioning or work participation in workers with other mental disorders could be identified. The same holds for predictors of work functioning among workers with somatic health disorders. However, a review of factors predictive of work participation in workers with chronic somatic disorders by Detaille et al. [44] revealed some similarities with findings from our review. In this review, factors predictive of work disability in somatic disorders 
included more severe health complaints (corresponding to more severe depression in our study), older age and sickness absence. In contrast to our findings, female gender was consistently shown to be related to unfavorable work participation. Another review reported factors affecting work participation for people absent from work due to mental health problems. Contrary to our review the authors included also mental health problems other than depression, non working groups (e.g., recently unemployed or students) and samples selected because of a physical health problem [45]. In line with our results this review shows that studies have produced opposing results in some cases, particularly in the case of demographic factors.

\section{Strengths}

To our knowledge, this is the first review on factors related to WP and WF in depressed workers. While Lerner and Henke [1] describe thoroughly the consequences of depression in terms of productivity and absence, this review aims to identify factors that can be used for the development of future interventions to prevent or reduce negative consequences of depression on work outcomes. In the level of evidence synthesis, and similar to the method used by Franche and colleagues [46], we transparently weighted the quality of the study based on the research design (cross-sectional versus longitudinal). This strategy addresses the limitation of cross-sectional research to draw conclusions about prospective relationships, without ignoring a substantial part of the available evidence in this field that is characterized by a limited number of relevant studies. In addition, no arbitrary cut-off scores for low versus high quality studies were used in line with the recommendations by Sanderson [38].

This review describes a broad range of work outcomes including both work participation and work functioning in a sensitive and comprehensive literature search using multiple databases. Despite the fact that WP and WF form a continuum, they seem to be artificially separated in most existing literature. Indeed, only 5 of the 30 studies selected in this review described WP and WF outcomes simultaneously.

It should also be noted that the review was conducted by a multidisciplinary team, including researchers from different institutes, with different training and different cultural backgrounds. Combining these perspectives has contributed to the development of a comprehensive view on the related concepts of WP and WF.

\section{Methodological Considerations}

In the literature search we gathered data representing determinants of WP and WF in the specific target population of depressed workers. This demarcated search deliberately ignored the literature that addresses determinants for the onset of depression and determinants of work outcomes among depressed but non-working individuals (such as re-employment) or in a non-depressed worker population (such as absenteeism among workers with burnout). However, these studies may provide evidence from which ideas can be derived for the development of new occupational health interventions.

Another limitation concerns the definition and categorization of the work outcomes. To date, no gold standard or commonly accepted definition for the concepts of WP and WF exist. Based on other definitions, our outcome measures could have been categorized differently, possibly yielding different results. With regards to work disability, several indicators of sickness absence have been aggregated in this review. Research shows that even though many absence outcomes overlap, differences were found with respect to certain prognostic factors or outcomes of interventions [47, 48]. For example, the frequency of absence might tell something about the need for recovery, while the duration of absence might be more related to illhealth [49]. A comprehensive explanation for these differences cannot yet be given. To our knowledge, the overlap between WP and WF measures has not yet been studied within a population of depressed workers. We believe that the transparent categorization we used resulted in a comprehensive and clear view on WP and WF.

Some methodological problems have been encountered. First, the studies were designed differently which hinders the aggregation of findings. The difference between crosssectional and longitudinal designs has been transparently addressed through the weighting of the levels of evidence. We have been cautious not to interpret the established associations as prognostic relationships, but refer to them as 'related' or 'associated' factors. Only in cases of strong evidence, i.e., based on at least two longitudinal studies, we conclude that a predictive relation is present. Another important issue concerns the aggregation of results from studies partly based on univariate analyses and partly based on multivariate analyses. It can be assumed that studies using univariate models may find significant relationships for certain factors that might become non-significant in multivariate models. In our evidence synthesis, however, the results of these two types of analysis were combined. It becomes even more complicated when we take into account that the design of multivariate models and the selection for confounder control are often not well described and subject to different approaches.

With respect to the external validity of the studies, it must be noted that all studies were conducted in western industrialized countries, limiting generalization to other cultures and social security contexts. The relationships for which limited evidence was found were often based on 
studies from one country. As many countries differ with respect to their social security systems [49], the applicability of findings will vary for various contexts, as highlighted in the evidence-based medicine approach [50]. For example, European research on predictors or associated factors of return to work among employees with either physical or mental health problems shows that the impact of work characteristics differs in European countries [49]. It is encouraging, however, that the relationship supported with moderate to strong evidence in our review often stemmed from different countries.

\section{Implications and Recommendations for Practice}

The presented overview of factors may be useful for professionals to develop occupational health interventions for depressed workers. Some of the factors identified as possible predictors (such as the severity of the disorder, selfesteem and supervisory behavior) are modifiable within a clinical or work setting.

The severity of the disorder may be improved when evidence-based (guideline-concordant) clinical care is available and implemented [51-53]. Unfortunately, this is not realized in all westernized countries [54]. In this paper, several indices of the severity of mood disorders were considered as related factors. The strongest level of evidence relating mood disorders to the outcomes of interest was for the relationship between duration of depression and work participation. This suggests that while the severity of symptoms/disorder is of importance, what may be driving the impact of depression on work participation might be the duration of the episode. The longer an episode of mood disorder, the longer a person is away from the social network of work and from work goals and activities. Over time, this erodes job attachment, considered to be a critical element of the worker-workplace relationship to the return-to-work process. These findings also have practical implications. Many available interventions are targeting, and successfully reducing, depressive symptom severity. However, it appears to be equally important to reduce the duration of the mood disorder episodes. Several strategies can be considered (1) Improve knowledge of health providers about diagnosis of depression: In many countries, there is a notable underdiagnosis of depression in primary care patients [55-59] and absence of diagnosis will delay obtaining treatment and prolong episode duration. (2) Improve access to appropriate psychiatric care and reduce delays in treatment delivery: Among those with a depression diagnosis, treatment provision has been shown to be inadequate [54-60], which can, of course, also prolong duration of depressive episode. (3) Increase general awareness about depression: Workers may delay seeking treatment due to lack of knowledge about depression or due to social stigma [61, 62]. Increasing their knowledge about the significance of their own symptoms, and fostering more tolerance in society about disclosure of depression may lead to speedier access to treatment, and reduce episode duration. (4) Facilitate access to treatment through workplace channels: Making it easier for the worker to disclose depression and access treatment via workplace channels may impact on speed of diagnosis and treatment delivery.

Besides intervening on the severity of the disorder, our findings suggest that personal factors like self-esteem and self-efficacy, and work-related factors like supervisory behavior could receive extra attention when designing interventions. Cognitions about the self-concept can be changed in a clinical setting and in the workplace. In the workplace, a supervisor could provide positive feedback to enhance self-esteem. Self-efficacy could be stimulated by adapting work tasks in such a way that work-related success experiences are guaranteed; and supervisors could be instructed to contact other health professionals besides the occupational physician when workers experience a clinical depression [63].

A recent Cochrane review [27] showed that the evidence for the effectiveness of existing clinical worker-directed interventions to improve work outcomes is limited. Moreover, no studies on work-directed interventions were identified. Therefore, it would be interesting to explore the impact of intervening on both personal and work-related factors to enhance work outcomes.

\section{Recommendations for Future Research}

Only a few factors, which had been identified a priori by occupational health experts, were actually present in scientific literature [31]. With respect to personal factors, modifiable concepts such as cognitions (e.g., perceived competence, self-efficacy and perfectionism) and skills (e.g., coping and problem solving) could be considered in future research. Future prognostic and intervention studies also should pay more attention to work-related factors. In the development of interventions, it is advisable to focus on modifiable factors such as work demands (e.g., work pressure, mental or emotional demands), work resources (e.g., financial rewards, social support, autonomy, security), types of tasks (e.g., working with clients/customers versus administrative work), physical workplace characteristics (e.g., day light), workplace culture (e.g., supervisory behavior, leadership style, organizational justice), and availability of work. Of these work-related factors, supervisory behavior might be a promising factor, because we found some evidence for a relationship with work participation. Studies of sick-listed workers with physical disorders have shown a relationship between supportive supervisory behavior and work disability. For example, 
early contact between the supervisor and worker, and contact by a healthcare provider with the workplace can prevent work disability [46]. However, within a subgroup of workers with adjustment disorders, frequent contact by the supervisor during sick leave increased time until full RTW in the subgroup of depressed workers [63]. As our finding regarding supervisory behavior for depressed workers is based on one single study, we recommend a replication of this study. Work-related factors such as high job stress and reorganizational stress have been associated with work disability among sick-listed workers with poor mental health in general [45], and could therefore also be addressed.

With respect to the outcome measures, several recommendations can be made for future research. In all, more attention should be paid to WP outcomes besides work disability, such as early retirement. Either from the WP or the WF perspective, the career development of depressed workers might be a topic of interest [64], using for example decreased promotion prospects or turnover to lower functions as outcome measures. Moreover, when the body of literature in this field increases, future reviews or metaanalyses might consider using more detailed categorizations of work outcomes. Broadening and differentiating the work outcomes, taking the complexity and developmental nature of these concepts into account, might improve our understanding and might contribute to better interventions. For instance, future studies could differentiate between shortterm (temporal) and long-term (permanent) disability [65, 66] or address different stages in the return to work process [67]. Future studies could integrate both types of work outcomes in their longitudinal research designs, ideally in a multicenter study with participation from multiple countries. Such designs may contribute to a better conceptualization of WP and WF from an international perspective and to the identification of common predictive factors for both outcomes in depressed workers. Longitudinal studies that combine WP and WF may be of additional value because they may provide better insight in the relative impact of depression on both work outcomes [22,68], the relative or combined impact of WP and WF on depression-related costs for employers [68], or in the mechanisms explaining the adverse depression outcomes over time [11, 22]. In addition, future studies on the effectiveness of occupational health interventions should incorporate both WF and WP to provide a comprehensive evaluation.

\section{Conclusion}

This review provides support for several associations between personal, work-related or disorder-related factors, and work outcomes. With respect to work participation, moderate to strong evidence was found for an association between a long duration of the depressive episode, more severe types of depressive disorders, presence of co-morbid mental or physical disorders, older age, history of previous sick leave, and the outcome of work disability. With regards to work functioning, more severe depressive symptoms were associated with more work limitations, and less clinical improvement was related to a reduction of work productivity (moderate evidence). The results of this literature overview can be used to develop new evidencebased interventions.

We recommend conducting more longitudinal, multicenter studies to identify predictive factors of WP and WF in depressed workers. In particular, studies should focus on modifiable personal and work-related factors and should address a broader variety of WP outcomes, e.g., change of jobs and career perspectives. In addition, WF and especially work productivity, should be studied more often.

Acknowledgments We would like to thank Amika Singh, Colette Severin, Gabe de Vries, and Wendy Ooteman for their contributions to this project. This project was partly funded by NWO and the Dutch Ministry of Social Affairs and Employment.

Open Access This article is distributed under the terms of the Creative Commons Attribution Noncommercial License which permits any noncommercial use, distribution, and reproduction in any medium, provided the original author(s) and source are credited.

\section{Appendix 1}

See Table 5 .

Table 5 Search string

\author{
General \\ Time period: $1995-2008$ \\ Search machines: PsycINFO, PubMed (Medline), Scopus \\ Language: English \\ Adult population \\ NOT (schizophrenia OR postpartum) \\ Words in title or abstract or thesaurus term (PsycINFO + Medline) \\ Words in title or abstract or keyword (Scopus)
}


Table 5 continued

\begin{tabular}{|c|c|c|}
\hline Medline & PsycINFO & Scopus \\
\hline \multicolumn{3}{|l|}{ Depression search terms } \\
\hline $\begin{array}{l}\text { 1. exp depressive disorder/ } \\
\text { 2. exp DEPRESSION/ } \\
\text { 3. exp adjustment disorders/ } \\
\text { 4. exp mood disorders/ } \\
\text { 5. exp affective symptoms/ } \\
\text { 6. depressed } \\
\text { 7. depressive symptoms } \\
\text { 8. } 1 \text { or } 2 \text { or } 3 \text { or } 4 \text { or } 5 \text { or } 6 \text { or } 7\end{array}$ & $\begin{array}{l}\text { \#8(explode neurotic depressive reaction/) or (explode dysthymic } \\
\text { disorder) or ("depression (emotion)") or (explode major } \\
\text { depression) or (explode affective disorders) or (explode recurrent } \\
\text { depression) or (explode reactive depression) } \\
\text { \#7explode recurrent depression } \\
\text { \#6explode reactive depression } \\
\text { \#5explode neurotic depressive reaction/ } \\
\text { \#4explode dysthymic disorder } \\
\text { \#3“depression (emotion)" } \\
\text { \#2explode major depression } \\
\text { \#1explode affective disorders }\end{array}$ & $\begin{array}{l}\text { Depressive disorder* } \\
\text { Depression } \\
\text { Adjustment disorder* } \\
\text { Mood disorder* } \\
\text { Affective symptom* } \\
\text { depressed } \\
\text { depressive symptom* } \\
\text { Reactive depression* } \\
\text { Dysthymic disorder* } \\
\text { Recurrent disorder* }\end{array}$ \\
\hline
\end{tabular}

\begin{tabular}{|c|c|c|}
\hline \multicolumn{3}{|c|}{ Work functioning search terms } \\
\hline Work performance & Work ability & Work impairment \\
\hline Productivity & Workability & Vocational impairment \\
\hline Lost productivity & Work performance & Vocational functioning \\
\hline Reduced productivity & Vocational outcome & Work limitations \\
\hline Light duty & Employment outcome & Occupational functioning \\
\hline Work cutback & Modified work & Work role functioning \\
\hline Cutback days & Job accommodation & Performance evaluation \\
\hline Presenteeism & & Extra effort \\
\hline \multicolumn{3}{|l|}{ Job performance } \\
\hline \multicolumn{3}{|l|}{ Vocational performance } \\
\hline \multicolumn{3}{|c|}{ Same in all 3 search engines } \\
\hline \multicolumn{3}{|c|}{ Work participation search terms } \\
\hline Sick* AND leave & Suboptimal employment & Work re-entry \\
\hline Sick* AND absence & Work disability & Employment \\
\hline Absenteeism & Work capacity evaluation & Employee \\
\hline Absence from work & Disability benefits & Work adjustment training \\
\hline Period of sick leave & Disability pension & Occupational intervention \\
\hline Return to work & Disability duration & Unemployment \\
\hline Turnover & Work status & Workplace \\
\hline Getting fired & Employment status & Occupations \\
\hline Demotion & Retirement & Work \\
\hline Lower function & Reemployment & Vocational \\
\hline Lower salary & Job re-entry & Occupational \\
\hline New job & Job turnover & Vocational rehabilitation \\
\hline Leaving job & Work turnover & \\
\hline
\end{tabular}




\section{Appendix 2}

See Table 6.

Table 6 Results from the quality assessment

\begin{tabular}{|c|c|c|c|c|c|c|c|c|c|c|c|c|c|}
\hline & Study ID & Outcome & & $y$ as & sme & iter & & & & & & & \\
\hline & & & 1 & 2 & 3 & 4 & 5 & 6 & 7 & 8 & 9 & 10 & Total \\
\hline 1 & Birnbaum et al. [69] & WP & 1 & 1 & 1 & 1 & 1 & 1 & 0 & 0 & 0 & 0 & 6 \\
\hline 2 & Buist-Bouwman et al. [70] & WP & 1 & 1 & 1 & 1 & 1 & 1 & 1 & 1 & 1 & 0 & 9 \\
\hline 3 & Dewa et al. [71] & WP & 1 & 1 & 1 & 1 & 1 & 1 & 1 & 0 & 1 & 0 & 8 \\
\hline 4 & Dewa et al. [72] & WP & 1 & 0 & 1 & 1 & 1 & 1 & 1 & 1 & 1 & 1 & 9 \\
\hline 5 & Druss et al. [12] & WP & 1 & 1 & 1 & 1 & 0 & 1 & 1 & 1 & 1 & 0 & 8 \\
\hline 6 & Kruijshaar et al. [42] & WP & 1 & 1 & 1 & 1 & 1 & 1 & 0 & 1 & 1 & 0 & 8 \\
\hline 7 & Laitinen-Krispijn and Bijl [43] & WP & 1 & 1 & 1 & 1 & 1 & 1 & 1 & 1 & 1 & 1 & 10 \\
\hline 8 & Lepine et al. [41] & WP & 1 & 0 & 1 & 1 & 1 & 0 & 0 & 0 & 1 & 0 & 5 \\
\hline 9 & Nieuwenhuijsen et al. [63] & WP & 1 & 0 & 1 & 1 & 1 & 1 & 1 & 1 & 1 & 1 & 9 \\
\hline 10 & Rytsälä et al. [73] & WP & 1 & 1 & 1 & 1 & 1 & 1 & 1 & 1 & 0 & 0 & 8 \\
\hline 11 & Rytsälä et al. [74] & WP & 1 & 1 & 1 & 1 & 1 & 1 & 1 & 1 & 0 & 1 & 9 \\
\hline 12 & Simon et al. [40] & WP & 1 & 1 & 1 & 1 & 1 & 1 & 1 & 1 & 1 & 1 & 10 \\
\hline 13 & Sorvaniemi et al. [75] & WP & 1 & 1 & 1 & 1 & 1 & 1 & 1 & 0 & 1 & 0 & 8 \\
\hline 14 & Souêtre et al. [76] & WP & 1 & 1 & 1 & 1 & 1 & 1 & 1 & 0 & 1 & 0 & 8 \\
\hline 15 & Claassen et al. [77] & WP/WF & 1 & 0 & 1 & 1 & 1 & 1 & 1 & 1 & 1 & 0 & 8 \\
\hline 16 & Druss et al. [68] & WP/WF & 0 & 1 & 0 & 0 & 1 & 1 & 1 & 1 & 1 & 1 & 7 \\
\hline 17 & Lerner et al. [11] & WP/WF & 1 & 1 & 1 & 1 & 1 & 1 & 1 & 0 & 1 & 1 & 9 \\
\hline 18 & Sanderson et al. [22] & WP/WF & 1 & 1 & 1 & 1 & 1 & 1 & 1 & 1 & 0 & 1 & 9 \\
\hline 19 & Stewart et al. [21] & WF/WF & 1 & 1 & 1 & 1 & 1 & 1 & 0 & 0 & 0 & 0 & 6 \\
\hline 20 & Adler et al. [24] & WF & 1 & 1 & 1 & 1 & 1 & 1 & 1 & 1 & 0 & 1 & 9 \\
\hline 21 & Endicott and Nee [78] & WF & 0 & 0 & 1 & 1 & 1 & 1 & 0 & 0 & 0 & 0 & 4 \\
\hline 22 & Hawthorne et al. [79] & WF & 1 & 1 & 1 & 1 & 1 & 1 & 1 & 0 & 1 & 0 & 8 \\
\hline 23 & Kornstein et al. [80] & WF & 1 & 0 & 1 & 1 & 1 & 1 & 1 & 1 & 1 & 0 & 8 \\
\hline 24 & Lerner et al. [81] & WF & 1 & 1 & 1 & 1 & 1 & 1 & 1 & 1 & 1 & 0 & 9 \\
\hline 25 & Michon et al. [82] & WF & 1 & 1 & 1 & 1 & 1 & 1 & 1 & 1 & 1 & 1 & 10 \\
\hline
\end{tabular}

$W F$ work functioning, WP work participation

Scoring: $1=$ positive, $0=$ negative or unable to determine

Quality assessment criterion

$1=$ Main features of the study population are stated

$2=$ Participation/response rate (at baseline) is at least $50 \%$

$3=$ Depression is assessed using standardized questionnaire or diagnostic classification system

$4=$ Predictive factor is clearly defined

$5=$ Work outcome (WF or WP) is clearly defined

$6=$ Statistical model used is appropriate for the outcome studied

$7=$ Statistical significance of association are tested and relevant parameters are presented

$8=$ Study controls for relevant confounding factors

$9=$ Number of cases in the analysis is at least 10 times the number of independent variables

$10=$ Research question is answered with longitudinal data 


\section{References}

1. Lerner D, Henke RM. What does research tell us about depression, job performance, and work productivity? J Occup Environ Med. 2008;50(4):401-10.

2. Bijl RV, Ravelli A, van Zessen G. Prevalence of psychiatric disorder in the general population: results of the Netherlands Mental Health Survey and Incidence Study (NEMESIS). Soc Psychiatry Psychiatr Epidemiol. 1998;33(12):587-95.

3. Alonso J, Angermeyer MC, Bernert S, Bruffaerts R, Brugha TS, Bryson $\mathrm{H}$ et al. Prevalence of mental disorders in Europe: results from the European Study of the Epidemiology of Mental Disorders (ESEMeD) project. Acta Psychiatr Scand. 2004;109(Suppl. 420):21-7.

4. Kessler RC, Merikangas KR, Wang PS. The prevalence and correlates of workplace depression in the national comorbidity survey replication. J Occup Environ Med. 2008;50(4):381-90.

5. Goetzel RZ, Ozminkowski RJ, Sederer LI, Mark TL. The business case for quality mental health services: why employers should care about the mental health and well-being of their employees. J Occup Environ Med. 2002;44(4):320-30.

6. Eaton WW, Martins SS, Nestadt G, Bienvenu OJ, Clarke D, Alexandre P. The burden of mental disorders. Epidemiol Rev. 2008;30:1-14.

7. D'Souza RM, Strazdins L, Broom DH, Rodgers B, Berry HL. Work demands, job insecurity and sickness absence from work. How productive is the new, flexible labour force? Aust $\mathrm{N} \mathrm{Z} \mathrm{J}$ Public Health. 2006;30(3):205-12.

8. Bultmann U, Rugulies R, Lund T, Christensen KB, Labriola M, Burr H. Depressive symptoms and the risk of long-term sickness absence: a prospective study among 4747 employees in Denmark. Soc Psychiatry Psychiatr Epidemiol. 2006;41(11):875-80.

9. Bultmann U, Christensen KB, Burr H, Lund T, Rugulies R. Severe depressive symptoms as predictor of disability pension: a 10-year follow-up study in Denmark. Eur J Public Health. 2008; 18(3):232-4.

10. Dooley D, Prause J, Ham-Rowbottom KA. Underemployment and depression: longitudinal relationships. J Health Soc Behav. 2000;41(4):421-36.

11. Lerner D, Adler DA, Chang H, Lapitsky L, Hood MY, Perissinotto $\mathrm{C}$, et al. Unemployment, job retention, and productivity loss among employees with depression. Psychiatr Serv. 2004; 55(12):1371-8.

12. Druss BG, Rosenheck RA, Sledge WH. Health and disability costs of depressive illness in a major U.S. corporation. Am J Psychiatry. 2000;157(8):1274-8.

13. Nieuwenhuijsen K, Verbeek JH, De Boer AG, Blonk RW, van Dijk FJ. Predicting the duration of sickness absence for patients with common mental disorders in occupational health care. Scand J Work Environ Health. 2006;32(1):67-74.

14. el-Guebaly N, Currie S, Williams J, Wang J, Beck CA, Maxwell $\mathrm{C}$, et al. Association of mood, anxiety, and substance use disorders with occupational status and disability in a community sample. Psychiatr Serv. 2007;58(5):659-67.

15. Ettner S, Frank R, Kessler R. The impact of psychiatric disorders on labor market outcomes. Ind Labor Relat Rev. 1997;51:64-81.

16. Elinson L, Houck P, Marcus SC, Pincus HA. Depression and the ability to work. Psychiatr Serv. 2004;55(1):29-34.

17. Doshi JA, Cen L, Polsky D. Depression and retirement in late middle-aged U.S. workers. Health Serv Res. 2008;43(2):693713 .

18. Karpansalo M, Kauhanen J, Lakka TA, Manninen P, Kaplan GA, Salonen JT. Depression and early retirement: prospective population based study in middle aged men. J Epidemiol Community Health. 2005;59(1):70-4.
19. Lerner DJ. Measuring work role functioning. Second annual meeting of the international society for quality of life research: abstracts of the contributed papers. Qual Life Res 1995; 4(5): 455-60.

20. Amick BC III, Gimeno D. Measuring work outcomes with a focus on health-related productivity loss. In: Wittink H, Carr D, editors. Evidence, outcomes \& quality of life in pain treatment: a handbook for pain treatment professionals. London: Elsevier; 2007.

21. Stewart WF, Ricci JA, Chee E, Hahn SR, Morganstein D. Cost of lost productive work time among US workers with depression. JAMA. 2003;289(23):3135-44.

22. Sanderson K, Tilse E, Nicholson J, Oldenburg B, Graves N. Which presenteeism measures are more sensitive to depression and anxiety? J Affect Disord. 2007;101(1-3):65-74.

23. Kessler RC, Akiskal HS, Ames M, Birnbaum H, Greenberg P, RM A et al. Prevalence and effects of mood disorders on work performance in a nationally representative sample of U.S. workers. Am J Psychiatry 2006; 163(9):1561-68.

24. Adler DA, McLaughlin TJ, Rogers WH, Chang H, Lapitsky L, Lerner D. Job performance deficits due to depression. Am J Psychiatry. 2006;163(9):1569-76.

25. Burton WN, Pransky G, Conti DJ, Chen CY, Edington DW. The association of medical conditions and presenteeism. J Occup Environ Med. 2004;46(6 Suppl):S38-45.

26. Dewa CS, Lin E. Chronic physical illness, psychiatric disorder and disability in the workplace. Soc Sci Med. 2000;51(1):41-50.

27. Nieuwenhuijsen K, Bultmann U, Neumeyer-Gromen A, Verhoeven AC, Verbeek JH, van der Feltz-Cornelis CM. Interventions to improve occupational health in depressed people. Cochrane Database Syst Rev 2008; (2):CD006237.

28. Schene AH, Koeter MW, Kikkert MJ, Swinkels JA, McCrone P. Adjuvant occupational therapy for work-related major depression works: randomized trial including economic evaluation. Psychol Med. 2007;37(3):351-62.

29. World Health Organization. International classification of functioning, disability and health (ICF). Geneva: WHO; 2001.

30. Sanderson K, Nicholson J, Graves N, Tilse E, Oldenburg B. Mental health in the workplace: using the ICF to model the prospective associations between symptoms, activities, participation and environmental factors. Disabil Rehabil. 2008;7:1-9.

31. Lagerveld S, Nieuwenhuijsen K, Huijs J. Factoren van invloed op werkuitkomsten bij depressieve medewerkers: verslag van een expertmeeting [Factors influencing work outcomes among depressed workers: report of an expertmeeting]. Hoofddorp: TNO Arbeid; 2008.

32. American Psychiatric Association. Diagnostic and statistical manual of mental disorders. 4th ed. Washington, DC: APA; 1994.

33. World Health Organization. The ICD-10 classification of mental and behavioural disorders. Geneva: World Health Organization; 1992.

34. Beck AT, Steer RA. BDI: beck depression inventory manual. New York: Psychological Corporation; 1987.

35. Hamilton M. Development of a rating scale for primary depressive illness. British J Soc Clin Psychol. 1967;6(4):278-96.

36. Radloff LS. The CES-D Scale, a self-report depression scale for research in the general population. Appl Psychol Meas. 1977;3: 385-401.

37. Mallen C, Peat G, Croft P. Quality assessment of observational studies is not commonplace in systematic reviews. J Clin Epidemiol. 2006;59(8):765-9.

38. Sanderson S, Tatt ID, Higgins JP. Tools for assessing quality and susceptibility to bias in observational studies in epidemiology: a systematic review and annotated bibliography. Int $\mathrm{J}$ Epidemiol. 2007;36(3):666-76 
39. Ariens GA, van Mechelen W, Bongers PM, Bouter LM, van der Wal G. Psychosocial risk factors for neck pain: a systematic review. Am J Ind Med. 2001;39(2):180-93.

40. Simon GE, Revicki D, Heiligenstein J, Grothaus L, VonKorff M, Katon WJ, et al. Recovery from depression, work productivity, and health care costs among primary care patients. Gen Hosp Psychiatry. 2000;22(3):153-62.

41. Lepine JP, Gastpar M, Mendlewicz J, Tylee A. Depression in the community: the first pan-European study DEPRES (Depression Research in European Society). Int Clin Psychopharmacol. 1997; 12(1):19-29.

42. Kruijshaar ME, Hoeymansa N, Bijl RV, Spijker J, Essink-Bot ML. Levels of disability in Major Depression Findings from the Netherlands Mental Health Survey and Incidence Study (NEMESIS). J Affect Disord. 2003;77:53-64.

43. Laitinen-Krispijn S, Bijl RV. Mental disorders and employee sickness absence: the NEMESIS study. Netherlands Mental Health Survey and Incidence Study. Soc Psychiatry Psychiatr Epidemiol. 2000;35(2):71-7.

44. Detaille SI, Heerkens YF, Engels JA, van der Gulden JW, van Dijk FJ. Common prognostic factors of work disability among employees with a chronic somatic disease: a systematic review of cohort studies. Scand J Work Environ Health. 2009;35(4): 261-81.

45. Blank L, Peters J, Pickvance S, Wilford J, Macdonald E. A systematic review of the factors which predict return to work for people suffering episodes of poor mental health. J Occup Rehabil. 2008;18(1):27-34.

46. Franche RL, Cullen K, Clarke J, Irvin E, Sinclair S, Frank J. Workplace-based return-to-work interventions: a systematic review of the quantitative literature. J Occup Rehabil. 2005; 15(4):607-31.

47. van Rhenen W, Schaufeli WB, van Dijk FJ, Blonk RW. Coping and sickness absence. Int Arch Occup Environ Health. 2008; 81(4):461-72.

48. Landstad B, Vinberg S, Ivergard T, Gelin G, Ekholm J. Change in pattern of absenteeism as a result of workplace intervention for personnel support. Ergonomics. 2001;44(1):63-81.

49. Stress Impact. Integrated report of stress impact: on the impact of changing social structures on stress and quality of life: individual and social perspectives. 2006.

50. Glasziou P, Del Mar C, Salisbury J. Evidence-based medicine workbook. Finding and applying the best research evidence to improve patient care. London: BMJ Books; 2003.

51. Bauer MS. A review of quantitative studies of adherence to mental health clinical practice guidelines. Harv Rev Psychiatry. 2002;10(3):138-53.

52. Fortney J, Rost K, Zhang M, Pyne J. The relationship between quality and outcomes in routine depression care. Psychiatr Serv. 2001;52(1):56-62.

53. Whooley MA, Simon GE. Managing depression in medical outpatients. N Engl J Med. 2000;343(26):1942-50.

54. Wang PS, Berglund P, Kessler RC. Recent care of common mental disorders in the United States: prevalence and conformance with evidence-based recommendations. J Gen Intern Med. 2000;15(5):284-92.

55. Coyne JC, Schwenk TL, Fechner-Bates S. Nondetection of depression by primary care physicians reconsidered. Gen Hosp Psychiatry. 1995;17(1):3-12.

56. Kirmayer LJ, Robbins JM, Dworkind M, Yaffe MJ. Somatization and the recognition of depression and anxiety in primary care. Am J Psychiatry. 1993;150(5):734-41.

57. Ormel J, VonKorff M, Oldehinkel AJ, Simon G, Tiemens BG, Ustun TB. Onset of disability in depressed and non-depressed primary care patients. Psychol Med. 1999;29(4):847-53.
58. Perez-Stable EJ, Miranda J, Munoz RF, Ying YW. Depression in medical outpatients. Underrecognition and misdiagnosis. Arch Intern Med. 1990;150(5):1083-8.

59. Simon G, Ormel J, VonKorff M, Barlow W. Health care costs associated with depressive and anxiety disorders in primary care. Am J Psychiatry. 1995; 152(3):352-7.

60. Kessler RC, Zhao S, Katz SJ, Kouzis AC, Frank RG, Edlund M, et al. Past-year use of outpatient services for psychiatric problems in the National Comorbidity Survey. Am J Psychiatry. 1999; 156(1):115-23.

61. Collins KA, Westra HA, Dozois DJ, Burns DD. Gaps in accessing treatment for anxiety and depression: challenges for the delivery of care. Clin Psychol Rev. 2004;24(5):583-616.

62. Seelig MD, Katon W. Gaps in depression care: why primary care physicians should hone their depression screening, diagnosis, and management skills. J Occup Environ Med. 2008;50(4):451-8.

63. Nieuwenhuijsen K, Verbeek JH, De Boer AG, Blonk RW, van Dijk FJ. Supervisory behaviour as a predictor of return to work in employees absent from work due to mental health problems. Occup Environ Med. 2004;61(10):817-23.

64. Kravetz S, Dellario D, Granger B, Salzer M. A two-facetted work participation approach to employment and career development as applied to persons with a psychiatric disability. Psychiatr Rehabil J. 2003;26(3):278-89.

65. van Oostrom SH, Anema JR, Terluin B, de Vet HC, Knol DL, van Mechelen W. Cost-effectiveness of a workplace intervention for sick-listed employees with common mental disorders: design of a randomized controlled trial. BMC Public Health. 2008;8:12.

66. Dekkers-Sanchez PM, Hoving JL, Sluiter JK, Frings-Dresen MH. Factors associated with long-term sick leave in sick-listed employees: a systematic review. Occup Environ Med. 2008; 65(3):153-7.

67. Young AE, Roessler RT, Wasiak R, McPherson KM, van Poppel MN, Anema JR. A developmental conceptualization of return to work. J Occup Rehabil. 2005;15(4):557-68.

68. Druss BG, Schlesinger M, Allen HM Jr. Depressive symptoms, satisfaction with health care, and 2-year work outcomes in an employed population. Am J Psychiatry. 2001;158(5):731-4.

69. Birnbaum HG, Leong SA, Greenberg PE. The economics of women and depression: an employer's perspective. J Affect Disord. 2003;74(1):15-22.

70. Buist-Bouwman MA, de Graaf R, Vollebergh WA, Ormel J. Comorbidity of physical and mental disorders and the effect on work-loss days. Acta Psychiatr Scand. 2005;111(6):436-43.

71. Dewa CS, Goering P, Lin E, Paterson M. Depression-related short-term disability in an employed population. J Occup Environ Med. 2002;44(7):628-33.

72. Dewa CS, Hoch JS, Lin E, Paterson M, Goering P. Pattern of antidepressant use and duration of depression-related absence from work. Br J Psychiatry. 2003;183:507-13.

73. Rytsala HJ, Melartin TK, Leskela US, Sokero TP, LestelaMielonen PS, Isometsa ET. Functional and work disability in major depressive disorder. J Nerv Ment Dis. 2005;193(3):189-95.

74. Rytsala HJ, Melartin TK, Leskela US, Sokero TP, LestelaMielonen PS, Isometsa ET. Predictors of long-term work disability in major depressive disorder: a prospective study. Acta Psychiatr Scand. 2007;115(3):206-13.

75. Sorvaniemi M, Helenius H, Salokangas RK. Factors associated with being granted a pension among psychiatric outpatients with major depression. J Affect Disord. 2003;75(1):43-8.

76. Souetre E, Lozet H, Cimarosti I. Predicting factors for absenteeism in patients with major depressive disorders. Eur J Epidemiol. 1997;13(1):87-93.

77. Claassen CA, Trivedi MH, Rush AJ, Husain MM, Zisook S, Young E, et al. Clinical differences among depressed patients 
with and without a history of suicide attempts: findings from the STAR*D trial. J Affect Disord. 2007;97(1-3):77-84.

78. Endicott J, Nee J. Endicott Work Productivity Scale (EWPS): a new measure to assess treatment effects. Psychopharmacol Bull. 1997;33(1):13-6.

79. Hawthorne G, Cheok F, Goldney R, Fisher L. The excess cost of depression in South Australia: a population-based study. Aust N Z J Psychiatry. 2003;37(3):362-73.

80. Kornstein SG, Schatzberg AF, Thase ME, Yonkers KA, McCullough JP, Keitner GI, et al. Gender differences in chronic major and double depression. J Affect Disord. 2000;60(1):1-11.
81. Lerner D, Adler DA, Chang H, Berndt ER, Irish JT, Lapitsky L, et al. The clinical and occupational correlates of work productivity loss among employed patients with depression. J Occup Environ Med. 2004;46(6 Suppl):S46-55.

82. Michon HW, Ten HM, Kroon H, van Weeghelvan J, de Graaf R, Schene AH. Mental disorders and personality traits as determinants of impaired work functioning. Psychol Med. 2008;38(11): $1627-37$. 